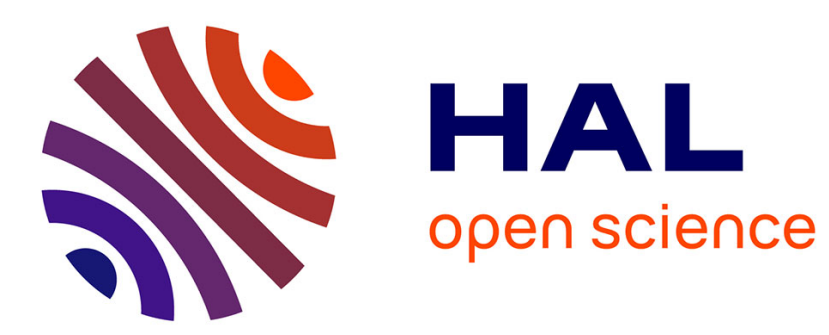

\title{
GROWTH KINETICS, CRYSTAL STRUCTURE, AND MORPHOLOGY OF OMVPE-GROWN HOMOEPITAXIAL CdTe
}

D. Snyder, P. Sides, E. Ko, S. Mahajan

\section{- To cite this version:}

D. Snyder, P. Sides, E. Ko, S. Mahajan. GROWTH KINETICS, CRYSTAL STRUCTURE, AND MORPHOLOGY OF OMVPE-GROWN HOMOEPITAXIAL CdTe. Journal de Physique IV Proceedings, 1991, 02 (C2), pp.C2-319-C2-326. 10.1051/jp4:1991239 . jpa-00249828

HAL Id: jpa-00249828

https://hal.science/jpa-00249828

Submitted on 1 Jan 1991

HAL is a multi-disciplinary open access archive for the deposit and dissemination of scientific research documents, whether they are published or not. The documents may come from teaching and research institutions in France or abroad, or from public or private research centers.
L'archive ouverte pluridisciplinaire HAL, est destinée au dépôt et à la diffusion de documents scientifiques de niveau recherche, publiés ou non, émanant des établissements d'enseignement et de recherche français ou étrangers, des laboratoires publics ou privés. 
Colloque C2, suppl. au Journal de Physique II, Vol. 1, septembre 1991

\title{
GROWTH KINETICS, CRYSTAL STRUCTURE, AND MORPHOLOGY OF OMVPE-GROWN HOMOEPITAXIAL CATE
}

\author{
D.W. SNYDER ${ }^{(1) *}$, P.J. SIDES*, E.I. KO* and S. MAHAJAN* * \\ "Department of Chemical Engineering, Carnegie Mellon \\ University, Pittsburgh, PA 15213, U.S.A \\ ** Metallurgical Engineering and Materials Science, Carnegie \\ Mellon University, Pittsburgh, PA 15213, U.S.A
}

\begin{abstract}
The growth rate, crystal structure, morphology, and electronic properties of homoepitaxial CdTe grown by OMVPE in an impinging jet reactor were investigated. Under operating conditions where surface reactions controlled the rate, the deposition rate depended on the diethyltelluride partial pressure to the .8 power and on the dimethylcadmium partial pressure to the .2 power, approximately. Cadmium was easily adsorbed and was ubiquitous on the surface during deposition; tellurium was relatively scarce on the surface. Deposition on three of the four low-index orientations proceeded at the same rate; CdTe grew on the (111) Te, however, at twice this rate. Hillocks were removed completely by deposition on a $(100)$ surface misoriented three degrees toward the (111) Te. Modeling of the fluid dynamics and mass transport in the reactor confirmed the high mass transfer rates obtainable with the impinging jet reactor; the mass transfer limited deposition, however, was nonuniform under the jet.
\end{abstract}

\section{Introduction}

We investigated the homoepitaxial growth of CdTe with an impinging jet reactor in order to elucidate the kinetics of the deposition, to model the transport and chemical reactions of the deposition process, and to characterize the deposited material. Many writers have contributed excellent work on this system over the past decade /1-7/. Our contributions are the exploration of an impinging jet reactor, the modelling of that reactor, the determination of some details of the kinetics of the reaction and, finally, the finding of a beneficial effect of misorientation on the morphology of the deposit /8-11/.

\section{Aspects of the Experiments}

A conventional gas distribution system, comprising bubblers, mass flow controllers, and an injection manifold, supplied reactants to an impinging jet reactor. A nozzle, 1.25 or $2.54 \mathrm{~cm}$ in diameter, directed the flow of the reactant mixture onto the substrate that rested on a heated pedestal directly belowand concentric with the nozzle. This configuration, which has been discussed theoretically and experimentally in the literature /12-14/, created an axisymmetric flow over the susceptor. Other researchers have also examined this geometry numerically $/ 15,16 /$. The impinging jet reactor is an interesting and useful variation for several reasons. One can achieve high mass transfer rates because the reactants impinge directly on the substrate. Unlike horizontal tubes, the impinging jet reactor does not depend on secondary flows perpendicular to the susceptor to bring the reactants to the surface. The high mass transfer rates allow the researcher to explore the reaction kinetics over a substantially larger temperature range at the same flow rate. Where horizontal tubes can involve three-dimensional flow patterns that must be solved on a supercomputer $/ 15 /$, we can solve the heat, mass, and momentum equations describing this axisymmetric system on a workstation. The parabolic flow profile emanating from the nozzle of the impinging jet reactor causes the mass transport to the susceptor to be nonuniform over the surface, which means that the impinging jet reactor is both a simple design for the laboratory and a "realistic reactor" because it possesses the nonuniformity attributes of commonly used reactors. 
Appearing in Fig. 1 is a detailed schematic of the reactor used in these studies $2 /$. Shown are the mechanism for changing the height of the reactor, the flow route, and the position of the load-lock port. The susceptor, already bearing the samples, was transferred to the hot stage from a load-lock port to one side by means of a linear translation arm. The load-lock isolated the reaction chamber from the outside, which increased the security of both the outside and inside environments. The effluent of the reactor passes through a particulate filter and into a carbon adsorber. The process was computer-controlled.

Two types of experiments were performed. First, we investigated the uniformity of deposition, which was measured by growing CdTe on a flat molybdenum susceptor placed onb top of the hot stage. After withdrawal of the "dummy wafer", all but a narrow band of the deposit was chemically etched from its surface. The vertical dimension of this band was measured by a profilometer at various radial positions. The remaining experiments were conducted with CdTe substrates embedded in a molybdenum "cassette" so the surfaces of the CdTe and Mo were flush. Two-Six, Inc. of Saxonburg, PA supplied the CdTe substrates that were subsequently polished with abrasives, chemi-mechanically etched, and finally dip-etched immediately prior to being placed in the reactor. The reactants were dimethylcadmium (DMCd), diethyltellurium (DETe) and hydrogen was the carrier gas. Experiments were conducted in the temperature range $290^{\circ} \mathrm{C}$ to $560^{\circ} \mathrm{C}$, the pressure range 100 to 760 torr, and partial pressures of reactants from 0 to .5 torr.

\section{Theoretical aspects}

The heat, mass, and momentum transfer in the impinging jet reactor were modeled with the aid of FLUENT/CVD, a computational fluid dynamics package marketed by Creare.X, Philadelphia, PA. A nonuniform grid containing 3220 cells was constructed to capture the most important features of the process. The analysis allowed for dependence of physical properties and reaction rate on temperature, pressure, and partial pressure of the alkyls.

\section{Results and discussion}

\section{Distribution of the deposit}

We experimentally analyzed the uniformity of the deposit on the substrate as a function of temperature of the substrate. Appearing in Fig. 2 is a sample of the deposition uniformity obtained in the impinging jet reactor when the rate of deposition was in mixed mass transfer and reaction control, and when it was controlled by mass transfer alone $/ 1 \%$. At $560^{\circ} \mathrm{C}$, the reaction rate was such that the deposition everywhere on the surface was limited by the rate at which convection and diffusion delivered reactants to the surface as indicated by the parabolic shape of the deposition rate as a function of position on the susceptor. At $460^{\circ} \mathrm{C}$, the area under the nozzle (indicated by the dotted lines in Fig. 2) experienced a high mass transfer rate so the deposition was limited by the rate of reaction in this region. Uniform deposition was obtained in the area because the rate was only a function of the surface temperature that was shown to be quite uniform $/ 1 /$. The surface outside this central region was much less accessible to reactants; hence the deposition rate was mass transfer controlled just as at $560^{\circ} \mathrm{C}$. These assessments of the controlling factors were confirmed by conducting experiments on growth rate as a function of temperature as shown in Fig. 3 11. The deposition was controlled by mass transfer above $500^{\circ} \mathrm{C}$ and the control was mixed around 460 ${ }^{\circ} \mathrm{C}$. Below $460^{\circ} \mathrm{C}$, the deposition rate exhibited Arrhenius behavior. The data are compared to data taken from Bhat $e t$ al. $\Pi /$ and found to be in agreement. The good mass transfer characteristics of the impinging jet, however, allowed the Arthenius region to be extended thirty degrees higher than the data of Bhat et al.

Appearing in Fig. 4 is a comparison of experimental data to the results of a numerical simulation of this case. The agreement between the model and the experiment was reasonable near the center but not good at the periphery. Two aspects of this comparison are noteworthy. First, many modellers have mentioned and used the property of uniform accessibility of the surface in the impinging jet geometry $/ 13,17,18 /$, but both the numerical simulation and the data indicated that the transport was nonuniform, even directly under the nozzle, when the flow from the nozzle emerged with a parabolic profile. Second, in the initial simulations, the predicted deposition rates were substantially higher than the experimentally measured rates. In fact, matching the predicted and experimental depositions required the use of diffusivities of the precursors in hydrogen that were a factor of 20 smaller than the values calculated from well-established correlations. We, like many investigators, however, had been assuming that the gas exiting the bubblers was saturated with alkyls. It seemed worthwhile, therefore, to challenge this assumption and, indeed, inventory of the alkyl, consumed in over 60 experiments, revealed that the actual concentration exiting the 


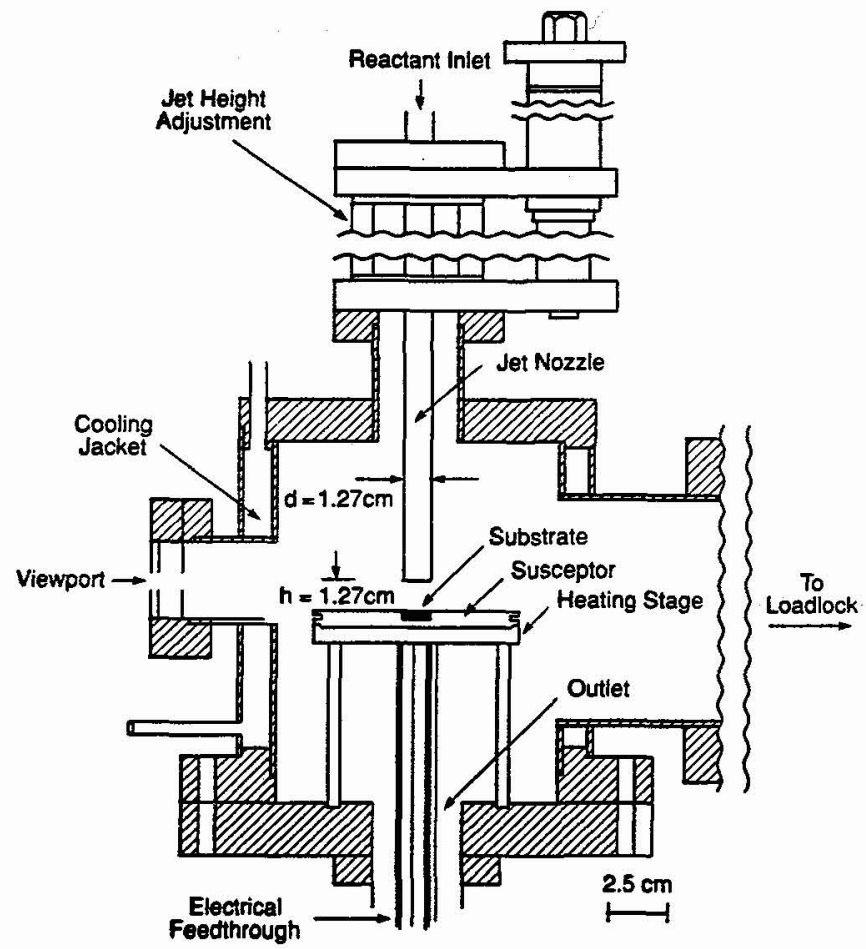

Figure 1. A sketch of the impinging jet reactor used for the OMVPE of CdTe

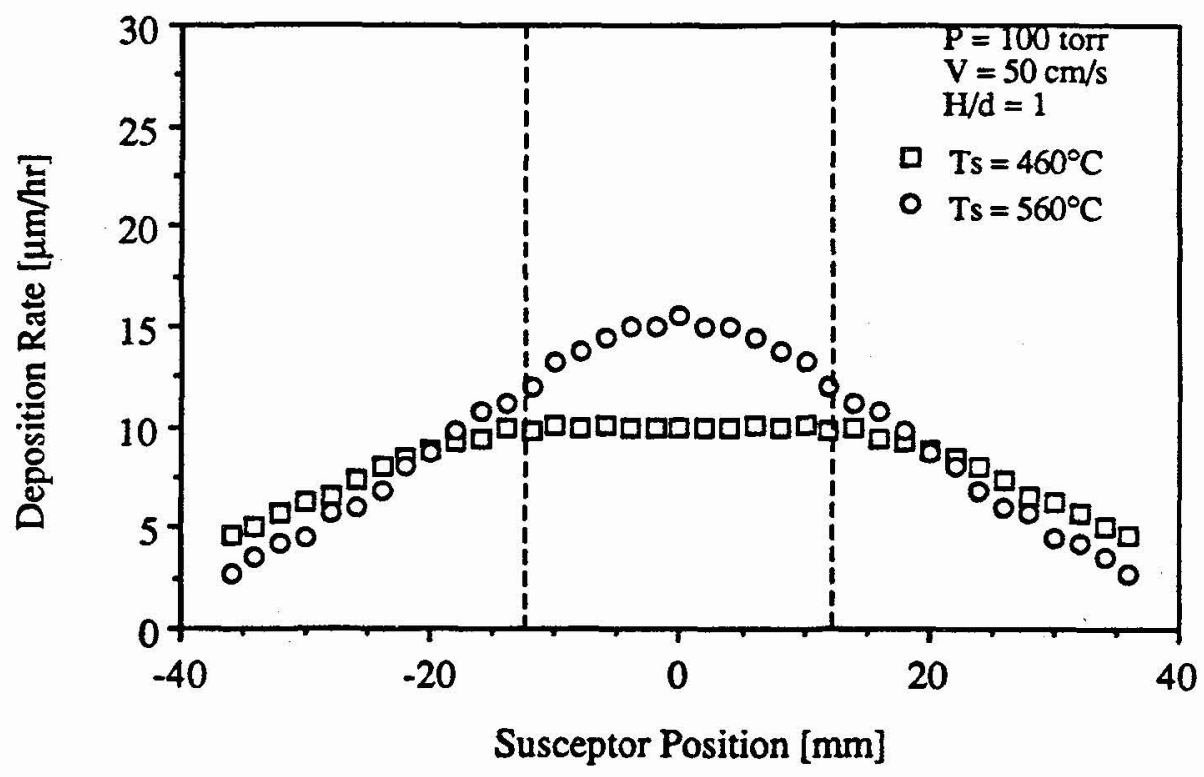

Figure 2. Effect of susceptor temperature on deposition rate profiles. $H / d=1, P=100$ torr, $\mathrm{v}=0.5 \mathrm{~m} / \mathrm{s}$ 


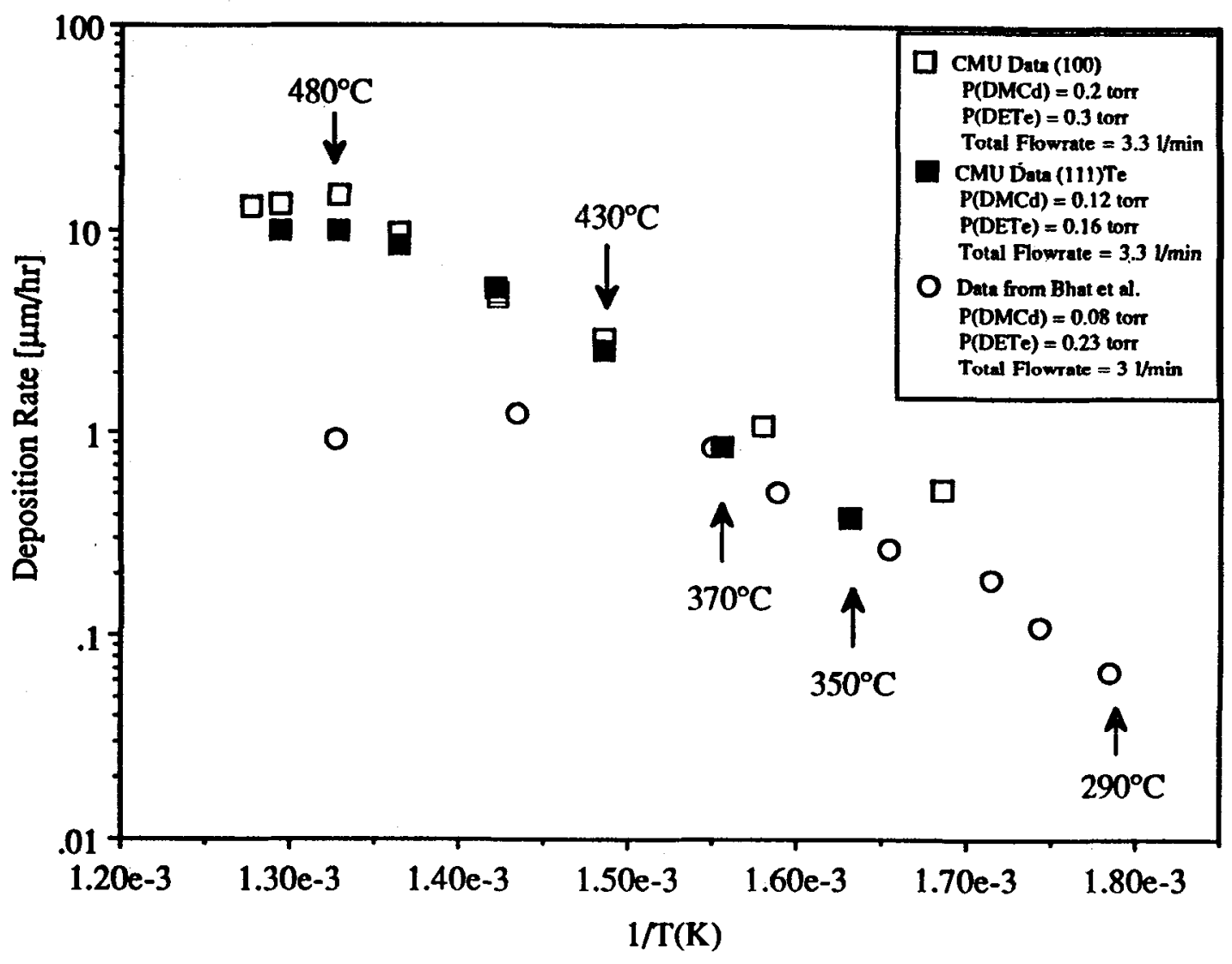

Figure 3. Arrhenius plot for OMVPE of CdTe on (111) $)_{\mathrm{Te}} \mathrm{CdTe}$ substrates 


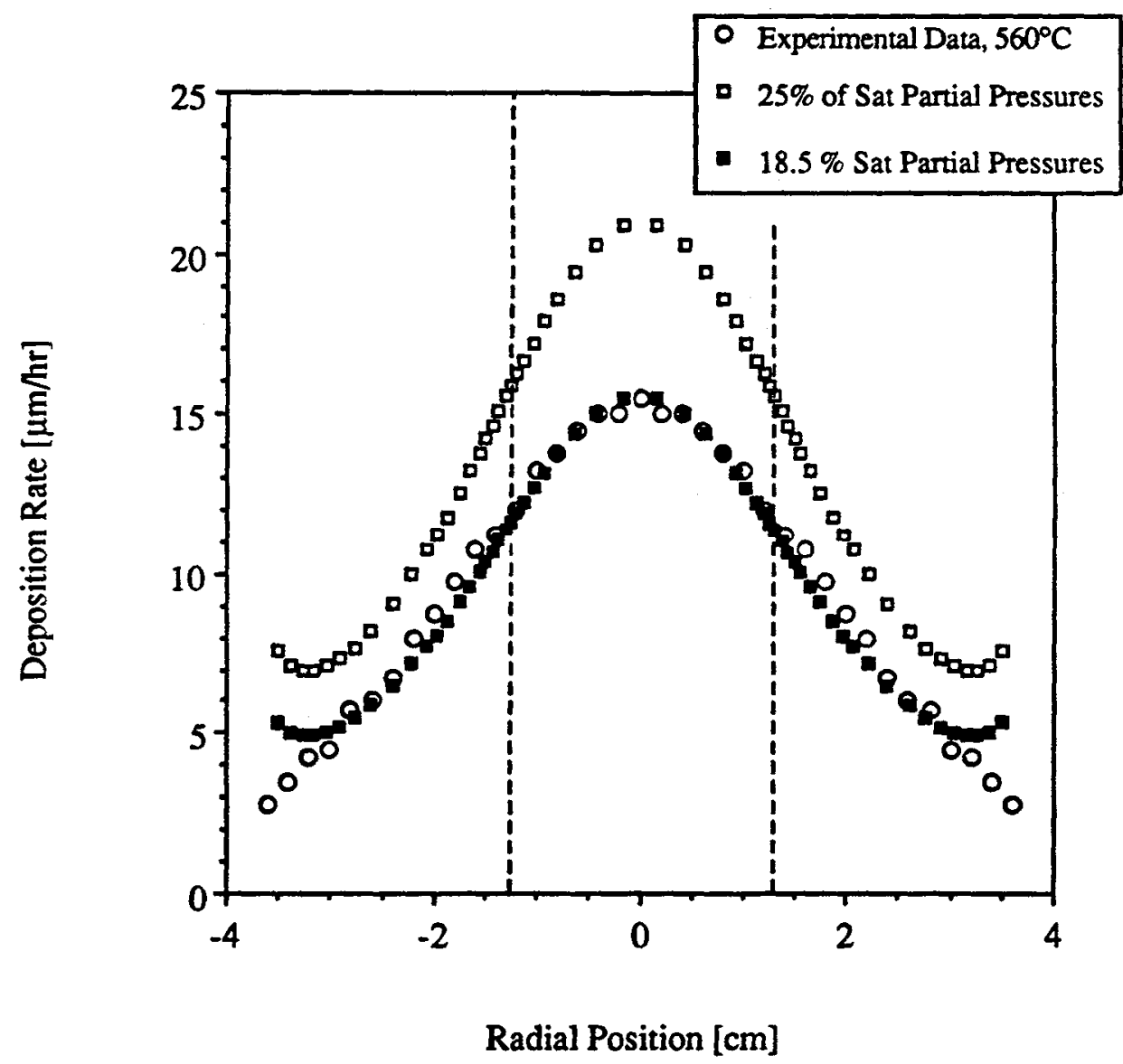

Figure 4. Plot of the experimental deposition rate and predicted deposition rates with $25 \%$ and $18.5 \%$ of the saturation partial pressures exiting the bubblers. $\mathrm{T}=560^{\circ} \mathrm{C}, \mathrm{P}=100$ torr, $\mathrm{H} / \mathrm{d}=1$ 
bubblers was approximately $25 \%$ of the expected value. When the diffusivity obtained from the correlation was accepted and the concentration exiting the bubblers was adjusted to $18.5 \%$ of the saturation concentration, we obtained the agreement shown in Fig. 4. Other simulations demonstrated the effect of pressure on the flow in the impinging jet reactor when both forced and natural convection were present. Appearing in Fig. 5 are streamlines calculated as a function of pressure from 1 torr to 720 torr when the fluid entered at $150^{\circ} \mathrm{C}$ and the susceptor surface was kept at $460^{\circ} \mathrm{C} / 1 \mathrm{p} 148 /$. The flow did not circulate below 100 torr but did begin to circulate between 100 torr and 410 torr.

\section{The reaction kinetics of film growth}

After examining the transport characteristics of the reactor and establishing conditions under which the rate of deposition was limited by chemical reaction at the surface, we studied the kinetics of OMVPE of $\mathrm{CdTe}$ as a function of the deposition conditions (pressure and temperature) and as a function of crystallographic orientation. The basic data appear in Table 1.

The experimentally determined rate laws for the various crystal planes suggested that surface combination of $\mathrm{Cd}$ and $\mathrm{Te}$ atoms limited the growth rate, with the relative ease of the decomposition of the two alkyls being reflected in the reaction orders, which were low for the cadmium alkyl and higher for the tellurium alkyl 11\%. The weak dependence of the deposition rate on the partial pressure of DMCd indicated a large fractional surface coverage of $\mathrm{Cd}$. The deposition rate depended strongly on the partial pressure of DETe, which indicated a small fractional surface coverage by the Te. The activation energy was in good agreement with the findings of others and also varied as a function of orientation. For given operating conditions, kinetically controlled deposition rates on the low index planes were the same on all but the $\{111\} \mathrm{Te}$ on which the rate was a factor of two higher except where mass transfer controlled the rate. This difference appears in Fig. 6. At all temperatures below the level at which mass transfer controls the growth rate, the (111) Te grew twice as fast as the other three low index planes. The growth rates for DETe and DIPTe were not significantly different in the temperature range from $350^{\circ} \mathrm{C}$ to $560{ }^{\circ} \mathrm{C}$. This lack of dependence on the Te precursor indicated the importance of the surface reactions in the temperature range of this study. Use of helium or nitrogen as a carrier gas decreased the deposition rate on all the orientations, which indicated a role of hydrogen in the chemical reactions $/ 1 /$.

\section{Effect of orientation on the quality of the film}

We investigated the dependence of deposit morphology on the crystal plane of the substrate. There were two principal results of this study. Deposits on the (100) orientation had the best structural and optoelectronic quality of the films grown on the low index orientations; however, crystallographic growth facets, referred to as hillocks, dominated the surface morphology of CdTe films deposited on this orientation. Misorientation from the [100] by $2.5^{\circ}$ to $4.5^{\circ}$ towards the nearest $[111] \mathrm{Te}$ suppressed the formation of hillocks and did not degrade the structural quality $13,4 /$. We found this striking effect by depositing CdTe on a [100] oriented CdTe substrate that had been polished in the shape of a spherical cap to reveal a continuous spectrum of misorientations from $0^{\circ}$ to $15^{\circ}$ from the $[100] / 4 /$.

Table 1. Effect or crystallographic orientation on the kinetic parameters of the growth of CdTe.

Parameter

Exponent on partial pressure of DMCd

Exponent on partial pressure of DETe

Activation Energy (Kcal/mol)
(100)

$$
.21 \pm .07
$$

$.70 \pm .11$

$19 \pm 2$
$.14 \pm .06$

$.73 \pm .10$

$17 \pm 6$
(111)Cd

$.26 \pm .08$

$.84 \pm .14$

$23 \pm 2$
(111) Te

$.01 \pm .10$

$.85 \pm .21$ 


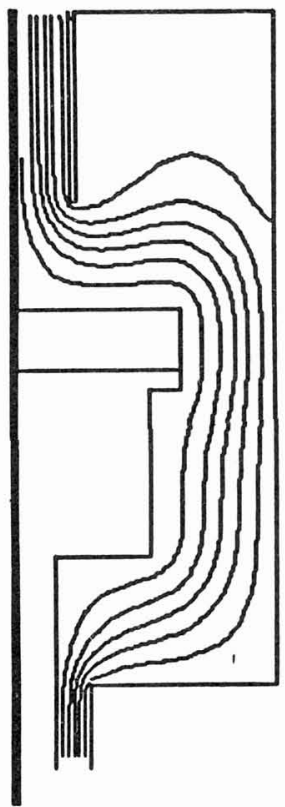

1 torr

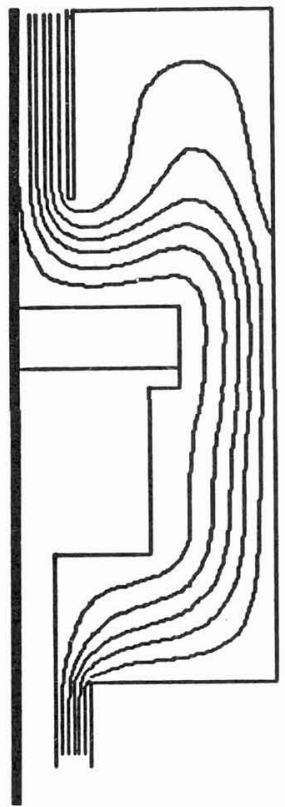

100 torr

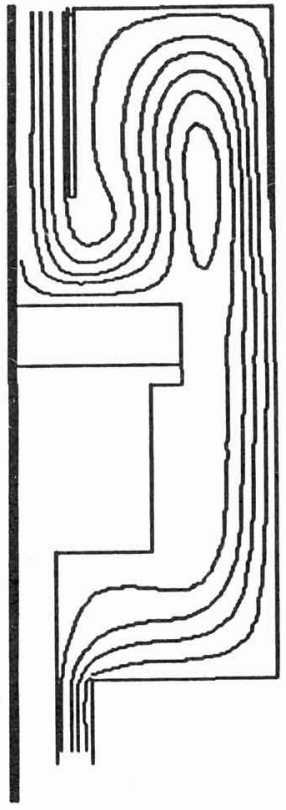

410 torr

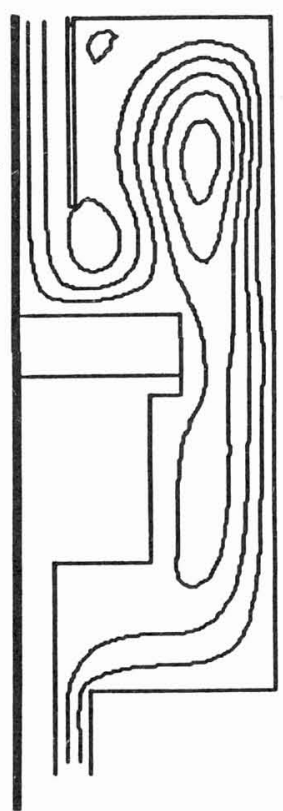

720 torr

\section{$2 \mathrm{~cm}$}

Figure 5. Streamlines for varying reactor pressures. $\mathrm{H} / \mathrm{d}=1, \mathrm{v}=.5 \mathrm{~m} / \mathrm{s}$, susceptor $\mathrm{T}=460^{\circ} \mathrm{C}$. 


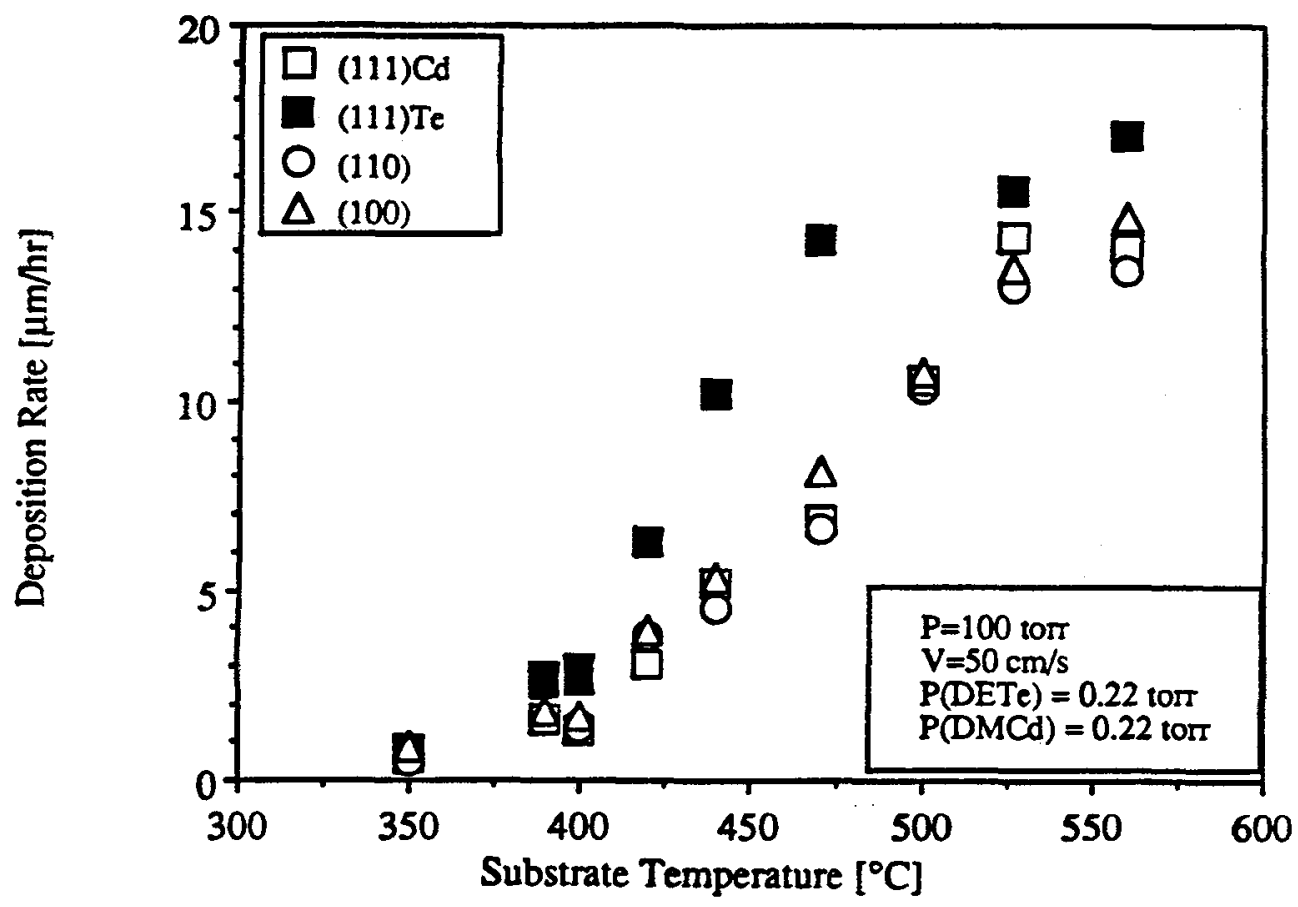

Figure 6. Deposition rate versus substrate temperature for CdTe growth on the four low index orientation using DMCd and DETe

\section{Conclusions}

The impinging jet reactor exhibited nonuniform growth when the deposition was controlled by mass transfer and uniform growth when the chemical reaction controlled the rate. Numerical simulations agreed with experimental data when careful attention was paid to the feed concentration. Growth of material on the (111) Te plane was twice as fast as on the three other low index planes. Adsorbed Cd was ubiquitous on the surface during growth; adsorbed Te much less so. Misorientation of the substrate from the (100) toward the $\{111\} \mathrm{Te}$ caused hillocks to vanish.

\section{Cited Literature}

/1/ Mullin J et al., J. Crystal Growth 55 (1981) 92.

12/ Kuznetsov P, et al. Izv. Akad. Nauk Neorg. Mater. 18 (1982) 779.

13/ Czerniak M and B. Easton, J. Crystal Growth 68 (1984) 128.

14/ Cole H et al., J. Appl. Phys. 55 (1984) 3166.

15/ Anderson P, J. Vac. Sci. Tech. A4 (1986) 2162.

16/ Wang C et al., J. Appl. Phys. 58 (1985) 757.

7) Bhat I et al., J. Electrochem. Soc. 134 (1987) 195.

18/ Snyder D, Metalorganic Chemical Vapor Deposition of Cadmium Telluride, Ph.d. Thesis, Carnegie Mellon University (1990).

19/ Snyder D et al., J. Appl. Phys. Let. 56 (1990) 1166.

/10/ Snyder D et al.,J. Appl. Phys. Let. 58848 (1991).

111/ Snyder D et al., Proc. Mater. Res. Soc. (accepted) (1990).

/12/ Scholtz M and O. Trass, AIChE J., 16 (1970) 82.

/13/ Vandenbulcke L and G. Vuillard, J. Electrochem. Soc., 124 (1977) 1931.

/14/ Chin D and C. Tsang, J. Electrochem. Soc. 125 (1978) 1641.

/15/ Jensen K et al., Annual Review of Fluid Mechanics Vol. 23 (1991) 197.

/16/ Wahl G Thin Solid Films 40 (1977) 13.

/17/ Jenkinson J and R. Pollard, J. Electrochem. Soc. 131 (1984) 2911.

/18/ Michaelidis M and R. Pollard J. Electrochem. Soc. 131 (1984) 860. 